\title{
Organizational memory as a mechanism of formation and development of organizational culture
}

\author{
Kateryna Myhaylyova ${ }^{1}$, Kateryna Bannikova ${ }^{2}$ \\ ${ }^{I}$ (Doctor of Sociology, prof., Sociology Department, People Ukrainian Academy, Ukraine) \\ ${ }_{2}^{2}$ (Post-graduate student, Sociology Department, People Ukrainian Academy, Ukraine)
}

\begin{abstract}
The paper develops the concept of organizational memory, which is seen as a mechanism for the development of organizational culture. Based on the analysis of the essence of the organizational culture and of the factors of its formation (primary, secondary, external, internal) the author shows the need to address the organizational memory as a phenomenon. The author suggests the interpretation of this phenomenon as a historical set of corporate values, knowledge, processes and phenomena that can be updated under certain conditions, as well as identified by all personnel in the organization according to the processes of the localization of the memories by any organizational entity. Attention is paid to the ratio of the individual and collective in the processes of organizational memory functioning. The conclusion about the need to differentiate the levels of collective and individual consciousness within the organizational memory analysis. Theoretical constructs by Emile Durkheim and Maurice Halbwachs are used for the conceptualization of the phenomenon. It is shown how the organizational memory is actualized in the course of organizational culture processes.
\end{abstract}

Keywords - mechanisms of functioning of the organizational culture, organizational culture, organizational culture factors, organizational memory

\section{INTRODUCTION}

The processes taking place in modern societies, actualize the issues related to the formation of new mechanisms of organizational development. The intangible assets become more and more important. And due to this more attention is given to the study of people, brands, image management, etc. However, these assets are today fairly well understood, largely replicable and therefore begin to give way to new components in the organizational development that can further emphasize the uniqueness of the organization, to give it the competitiveness through innovative solutions in respect of employees and other intangible assets.

One of these tools one can consider to be the organizational culture. The interest towards the issues of organizational culture exists due to the rapidly changing situation at the current economic and social space, which puts the company in front of the need to search for such management strategies that would allow as much as possible to respond quickly to the changes in the external environment. In such circumstances, the usual people management practices are not effective enough, which leads to the actualization of other factors that, in transforming corporate values system, may constitute a significant competitive advantage for any company and affect its effectiveness.

Currently, considerable theoretical and practical experience in scientific research of the processes of formation, maintenance, development of organizational culture has been accumulated. In this aspect, the work of the management classics such as Michael H. Mescon, Michael Albert, Franklin Khedouri, Elton Mayo, Edgar Schein should be mentioned. Talcott Parsons, John Hampton, Geert Hofstede, Douglas McGregor, Melville Dalton, Robert Quinn and others dedicated their works to the development of different aspects of organizational culture. In their theoretical thinking they focus on key characteristics of the organizational culture, as well as factors and mechanisms of its formation. However, the dynamics of our time determines the actualization of attention to this group of problems.

\section{ORGANIZATIONAL CULTURE AND THE MAIN FACTORS} OF ITS FORMATION

Talking about the organizational culture as an object of scientific understanding, it should be noted that in the scientific revolution, the term "organizational culture" was introduced by Talcott Parsons in 1956. The organization, considered as a system, by Talcott Parsons, is a stable complex of repetitive and interrelated social actions. The system as a whole and its elements perform functions determined by the objectives of the system and its structure. T. Parsons distinguishes four subsystems in the general system of social action: a biological organism, personality system, social system, cultural system. The elements of social action system form a hierarchy in which the cultural subsystem dominates, as values and social norms of society control the actions of 
its members and, thus, enable the collective social life. Thus, the cultural subsystem performs its normative function [1: 462]. Prior to the beginning of 1980s. the scholars who studied the issues of the organizations did not pay any particular attention to the concept of organizational culture. The activation of the study of this phenomenon was caused by the evolutionary development of human resources management, linked to the need to improve the work efficiency in a new environment. Therefore, the concept of "organizational culture" was actively included into the scientific language only in the early 70-ies of XX century.

A look at the scientific understanding of the organizational culture shows that there are very narrow (which include the understanding of the organizational culture as beliefs, norms of behavior, attitudes and values that are the unwritten rules governing how people should work and behave in the organization), and very wide interpretations of what a culture of the organization is (organizational culture as a unique template of a way of thinking, feelings and reactions which is inherent in the organization and its internal divisions). Most authors agree that the culture of an organization is a complex composition of important assumptions (often not amenable to formulation), which are without evidence accepted and shared by the members of a group or organization.

Often organizational culture is treated as the organizational philosophy and the management ideology, values, beliefs, expectations, and rules which are largely accepted in an organization and are underlying the relations and interactions both within the organization and outside it. Organizational culture is manifested in the relationship between people in the organization.

We agree with the statement that the organizational culture is, above all, a set of values, norms, symbols, which are the guidelines of behavior of employees. The values of the organization are at the base of the management decisions and production problems solutions; values and rituals system acts as a set of rules of the approved behavior of employees in an organization.

However, organizational culture is not monolithic neither it is developed linearly. It is structured and is influenced by various factors and mechanisms. That is why the result of the development of organizational culture in the company is seen only after a certain period of time.

Formation and change in organizational culture are influenced by many factors. Edgar Schein identifies five primary and five secondary factors that determine the formation of the organizational culture [2: 223-243]. The primary factors which he considers are:

1. The points of concentration of senior management attention.

2. Management response to critical situations that arise in the organization.

3. Attitude to work and style of managerial behavior.

4. Sets of criteria that employee incentives are based on.

5. Sets of criteria that talent acquisition and employee promotions and dismissals are based on in the organization.

The group of secondary factors, according to Edgar Schein, includes the following factors:

1. The structure of the organization.

2. Information transmission system and organizational procedures.

3. The exterior and interior design and decoration of the premises of the organization.

4. Myths and stories about important events and people that have played a key role in the life of the organization.

5. Formal provisions about the philosophy and the meaning of existence of the organization.

In our point of view, this classification of factors currently cannot be regarded as actually working. This is due to the fact that it, first of all, does not take into account environmental factors, which often have a strong influence on the "rules" within the organization. Secondly, these factors include the actual elements of the organizational culture (myths, legends, design, decoration of premises), which suggests that the organizational culture forms itself (which is logically false, if we are talking about the impact of factors on the object). Thirdly, in our opinion, not all the organizational internal entities that can reinforce or 'erode' organizational culture, support or change it, are included in the list of factors taken into consideration. Fourth, the characteristics of the individual processes (selection, promotion, evaluation, etc.) are presented as factors in the proposed classification. However, in our opinion, these procedures are constructed based on the provisions and principles of organizational culture, and not vice versa.

Nevertheless, the classification of the factors of the formation of organizational culture proposed by Edgar Schein contains important markers that can be taken into account in the study of organizational culture and its development in organizations.

Quite often you can find a different classification of factors influencing the organizational culture in the scientific literature $[3,4]$ First of all, the external and internal factors are spoken about. The former include: general economic conditions, competitors, investors, legislation, international and domestic political, economic and social situation, religion, domain in which the organization carries out its activities, the level of development of information technology in the society, ethnic processes, etc. Among them, the greatest attention is paid to socio-cultural factors. It is clear that external factors must be taken into consideration in the analysis 
of the organizational culture of modern organizations. However, along with external factors, a separate analysis of internal factors, which are partially indicated by Edgar Schein, should be made. In the most general terms, they can be divided into three groups: organizational factors, management factors and personnel-related factors (see Table 1).

Table 1

Internal factors affecting the formation and development of organizational culture

\begin{tabular}{|c|c|c|}
\hline Organizational factors & Management factors & Personnel factors \\
\hline $\begin{array}{l}\text { - History, ownership and size } \\
\text { of the company } \\
\text { - Goals and objectives of the } \\
\text { company } \\
\text { - Strategy } \\
\text { - Structure of the company } \\
\text { - Level of scientific and } \\
\text { technological development of } \\
\text { the company } \\
\text { - Nature and content of work } \\
\text { - Rapid growth of the } \\
\text { company; transition from a } \\
\text { family business to professional } \\
\text { management } \\
\text { - Internal and external design }\end{array}$ & $\begin{array}{l}\text { - Innovation policies } \\
\text { - Tools and methods used to achieve } \\
\text { the objectives } \\
\text { - Monitoring and establishing success } \\
\text { criteria for measuring progress of the } \\
\text { objectives } \\
\text { - System of employee motivation } \\
\text { - Creation of a creative atmosphere in } \\
\text { the team } \\
\text { - Personality and image of the leader } \\
\text { - Leadership styles } \\
\text { - Goals and values of the top } \\
\text { management of the company; attitude } \\
\text { to work and the type of response to } \\
\text { critical situations. } \\
\text { - Power, status, and establishing the } \\
\text { rules for the acquisition, maintenance } \\
\text { and loss of power; determination and } \\
\text { distribution of the statuses in the } \\
\text { company }\end{array}$ & $\begin{array}{l}\text { - Formal methods and systems } \\
\text { of communication; common } \\
\text { language of the employees and } \\
\text { organizational processes } \\
\text { - Qualifications, education and } \\
\text { the overall level of personnel } \\
\text { development } \\
\text { - Nature and content of work } \\
\text { - Boundaries of social groups } \\
\text { and criteria for entry and exit of } \\
\text { these groups } \\
\text { - Personal views of all } \\
\text { members of the company } \\
\text { - Local cultures of the units } \\
\text { and departments in the } \\
\text { company }\end{array}$ \\
\hline
\end{tabular}

This list clearly shows the influence of the typology by Edgar Schein. That is why it is partly subject to the same points of criticism, in particular, on the inclusion of elements of organizational culture in the list of factors of its formation. It should be noted that in the present list of internal factors are also reflected those that are not universal for the analysis of modern companies (for example, the transition from a family business to professional management, etc.).

It should be noted that in this typology are introduced the internal factors which can actually be significant in the development of organizational culture. First of all, it is the size of the organization, the scope of its operations, personnel and technology characteristics.

However, in modern conditions, in our opinion, there is a number of additional factors of internal nature that require the researcher's attention. Among them are communication system, resources, and informal leadership.

Thus, the factors affecting the formation and development of organizational culture are a system, where primary and secondary factors, external and internal factors are tightly intertwined. In modern conditions, not all of them have the same influence on the organizational culture, and special attention should be paid to the mechanisms of their impact, contributing to the formation and development of organizational culture.

\section{ORGANIZATIONAL MEMORY IN THE SYSTEM OF MECHANISMS OF ORGANIZATIONAL CULTURE FORMATION}

According to Edgar Schein, the following are the most powerful mechanisms for the initial establishment and consolidation of a culture:

- $\quad$ reaction of the leaders at the important incidents and crises;

- $\quad$ role modeling, training and education;

- criteria for distribution of remuneration and status changes;

- $\quad$ criteria for recruitment, selection, promotion and job offers;

- consolidation of existing values;

- introduction of new values into action through the planned events, such as the introduction of quality assurance and customer care programs;

- monetary and non-monetary rewards for desirable behaviors, performance improvement and rewarding good teamwork, development of a learning organization; 
- use of a system of values as a basis for reviewing the performance of individual employees and teams - while emphasizing that it is assumed that employees will uphold the values of the organization;

- ensuring that procedures of the acquaintance with the organization (introduction, orientation, adaptation) were covered by its core values and behaviors for achieving them;

- reinforcing the introductory training at further training courses, which are part of a continuous development program [2].

In conjunction with the factors set out above, these mechanisms contribute to the generation and development of organizational culture. However, in our opinion, yet another phenomenon requires to be included in this list, which is rarely mentioned in the studies on organizational culture and management - this is the organizational memory.

Some of the first to examine this phenomenon were Walsh and Ungson, who defined it as the method by which it is possible to hold, acquire and search for information in the organization. Their task was to make this phenomenon useful for decision making in management. To do this, they used a significant amount of research constructs and data based on the understanding of information and knowledge. The opinion of Walsh and Ungson states that organizational memory is both a collective and an individual phenomenon [5:61]. It is difficult to accept this statement because the memory is allocated to the subject, as it is its memory. And this is true for both collective and individual entities. Yes, their design can exploit the potential of each other, but at the level of definitions, they require accurate definition. That is why, in our opinion, the theoretical basis of the phenomenon of organizational memory needs to be improved.

In the course of its functioning and development, any organization goes through the way of accumulation and redistribution of the total employees' knowledge. This process actually arises first in the organizational and legal forms of the enterprise and during the formal registration of its main objectives, the formation of the capital and the formation of the key leaders. Further, it is constantly being improved, from the process of the organizational philosophy development to a specific application in the people management process, taking into account its specific features in any given point in time. As a result, the substances of "knowledge" and "experience" undergo the continuous improvement of its structural and content components.

Knowledge, skills and competencies of individual employees eventually move into an active phase of formation of the human capital of the organization, thereby outlining the dynamic determinant of social experience across the organization.

Considering these processes in time, we can state the fact that the same set of corporate knowledge, processes and phenomena can have a different meaning, and therefore meet the different system requirements and have a different nominal categorical row. So, if we analyze these processes in the present, we, first of all, will keep in mind the phenomenon of the human capital of the organization and its social experience. When considering these processes in the context of the past we will talk about this phenomenon as "organizational memory".

Under the organizational memory, we understand historically developed set of organizational values, knowledge, processes and phenomena that can emerge under certain conditions, as well as is identified by all employees in the organization according to the processes of memories localization by any organizational entity.

The methodological basis of this phenomenon can be a teaching of Emile Durkheim, who saw such things as collective consciousness and collective memory, as well as the concept of M. Halbwachs.

"The main challenge, which Durkheim described while emphasizing a fundamentally different basis of collective representations compared to individual ones, was to highlight the collective representations, which, in his opinion, embraced the kind of mental life, infinitely richer and more complex than the mental life of the individual. The individual is forced to use the collective representations, such as the set of collective representations - "collective consciousness" - causing the contents of the collective consciousness serve as the basis of his thinking and actions "[6].

Maurice Halbwachs emphasized that no society could live without a collective fund of memories, as all social institutions are held together by nothing more than the collective memories.

According to Maurice Halbwachs, events, processed by collective memory, obtain a kind of eternal significance, and therefore are remembered more often and longer than the personal memories of a particular subject.

Refracting the methodological approach to the problems of organizational memory, we can state that the processes and phenomena that have the character of collective in an organization remain in the history of the organization longer and are systemic in nature in the general functioning of the organization, rather than similar processes of the personal format.

In our opinion, in this context, the actualization of organizational unity and the search for general corporate ideas begins with the primary processes of the localization of the organizational memories. And here the question arises with regards to the framework of the organizational memory. 
According to M. Halbwachs, "under the framework of memory, we understand not only sets of ideas, which we can observe at any time, since they more or less exist in our consciousness field - but all those to which you can come, starting from the originals sets of ideas by using mental operations, similar to the simple reflection "[7 : 168]. However, M. Halbwachs not only clarifies the nature of memory localization process as an internal process, but also comes to a deductive conclusion that this fact is dependent on the social nature, namely: "The framework that we believe, enables us to reconstruct our memories after their disappearance are not, purely individual, they are common to members of the same group. If they are applied to all the recent developments, including them in full, so that any one of them can be taken at random as a reference point when they are in the same plane - hence the group as a whole remembers them all, then all of the most recent facts have for the group about an equal value "[7:169].

This means that organizational memory serves as some universal substantive field through which the logic of organizational development is built which influences the formation and development of organizational culture as well.

Like sociologists-functionalists, M. Halbwachs uses a systematic approach to the analysis of the functional orientation of each period in the life of community and reflects it in the context of the main collective sense - the collective memory.

We believe that the collective memory of the organization is not only functionally loaded as described above, but also reflects a system of meaningful cultural and value determinants corresponding to the entire organization and shared by all employees, regardless of their affiliation to a particular group, ethnic group, mentality, nationality, etc. For this reason, it is essential, in our opinion, to talk about the phenomenon of organizational memory, because it not only includes all the collective of each group, but is itself a direct element of the functioning and development of the organization.

On the other hand, while analyzing any social phenomena or facts that have occurred in the organization, we begin our immersion in the analytical process of updating the memories by asking such questions as: When was that? what day, month? this week or six months ago? What else was happening at this time in the organization? ...

In other words, we detalize the analysis of the possible time period, allowing us to find the right solution for a particular department or employee. The dive begins with a complete "oxygen cylinder" and we systemize the private time of an employee as well as the "social" time of the organization. We remember some details of the organization / unit / employee life cycle, to comprehend and relate to other cycles, which can be somehow correlated with the desired period or date in the life of the entire organization.

Then, according to the theory of Emile Durkheim, the collective consciousness of the organization includes a broad doctrinal system of socially determined attributes of the unity of time for the organization. This layer of the annals of the past includes all social facts, organizational processes and phenomena. Then, with the help of reverse action of isolating information from the collective consciousness we relate the facts obtained from the personal memories of a particular employee, after which there is a reflection on the required date or time period.

However, time itself is only one coordinate axis. In order to make the process of updating the memories logical and consistent it is necessary to expand its effective meaning. Effective sense, according to $\mathrm{M}$. Halbwachs, is expanded from the standpoint of rational and irrational images and directly from the "event", which should take place with the subject. "In addition, it is likely that since then I have been thinking about all this more than once, and among the many memories that I could be having since then, only two stand out with such prominence as they were better than others due to reflections linked the general conditions of my life at that time: therefore, it is worth recalling the general conditions that have come to mind in order to reveal the memories" [7:167].

To achieve this goal, you can very well use the structural elements of the organizational memory proposed by Walsh and Ungson [5:64]. These elements can be used as a fulcrum for the actualization of the collective memories.

Obviously, this paradigm and conceptual content in the context of organizational culture actualizes the analysis of the usage of the possibilities of the functional areas of sociological knowledge. As we know, functionalists believed that in addition to direct meaningful content and functional use of the processes, phenomena and facts in the society, the functional content of the same phenomena can be interpreted from the perspective of dysfunction or non-function [8]. At the same time the very essence of social phenomena will remain unchanged. In addition, dysfunctional process, according to scientists of this school, can evolutionarily develop the whole social structure, because the structure itself is adapted to the possible internal or external threats. The direct objective of such types of functions, as in our case with the actualization of memories, is the organization of a comprehensive analysis of all possible elements in the system of relationships among them, or the isolation of the necessary elements of a set of social phenomena and their consideration as other elements of the system from another set. 
In our view, organizational culture can be seen from this point of view, as a phenomenon, which, on the one hand, is formed and maintained through collective memories and organizational memory as a whole, and on the other is developed because of it. However, the mechanisms that contribute to this, may be varied. Among them - the "logical thinking" of a management entity. In this regard, M. Halbwachs noted that "for the localization of memories there is no other means of how to get back to pass in front of the whole chronological range of memories, in which it is included" [7:161]. "Such a state of consciousness should be more or less standing out from the crowd: and if so, then why not assume that all together they form a kind of system of stable relations and we pass from one to the other not by chance, but during a quite logical operation, such as the argument" [7 : 164]. In this context, it is the logic of making management decisions based on the phenomenon of organizational memory that provides the collective consciousness with the desired structure and systematic analysis. And the possible arguments, and other collective communication mechanisms are not only based on rational statements, but also on the results of the necessary social activity.

Reflections and analysis by the collective consciousness of a social fact, which has an organizational nature, have been influenced not only by the organizational elements, but also by the macrosocial phenomena. For example, immersed in the memories on the transition to a different organization of management accounting system, we come to think with respect to all existing accounting systems in a specific period of time as they relate to the then existing rules of legislative regulation of the issue. We analyze this process and argue about different possible accounting models, while it is not so important for the process of updating the memories. Indeed, in general, we are slowly gathering the different strands of the facts and are connecting them not only with the processes and phenomena, but with entities that have been included in them at the time.

In the present context such concepts are also possible which in fact did not exist but that could have existed, or we would like them to. Thus, we reveal the scope of the organizational memory, going through models of possible behavior and critical attitude towards the behavior of all actors involved.

A separate issue, when considering the organizational memory, is the emotional component of this phenomenon, in which an employee as a mono-subject and the organization as a poli-subject, experienced in the past some emotional burden. In this regard, M. Halbwachs writes: "Of course, an echo that was caused by these facts in all of us should be taken into account. Sometimes in the forefront of our minds are purely internal events, staying in our eyes as bright or dark marks that highlight the major dividing lines and sharp turns in our lives" $[7: 164-165]$. In other words, the identification of memories and their localization in time will happen faster in the event that these memories are based on certain strong emotional facts that occurred at the same time directly with the employee and the organization in the same time.

\section{CONCLUSION}

The process of formation of organizational culture is associated with the establishment of a certain type of relationship between the members of the organization while finding ways of working together. In this process the formation of values, traditions, established norms and rules of behavior, rituals, communication systems, language, motivation system takes place, which means that the desired behavior of employees within the organization is formed. In each organization, these processes have their own specificity, which determines the need to analyze the factors influencing these processes. In general, the analysis of the factors and mechanisms of formation and development of organizational culture has shown that it is possible to talk about the whole system of external and internal factors, which can be primary or secondary. Their analysis makes it possible to assume that the force of their impact will vary for different organizations. However, organizational memory holds a special place in the system of these mechanisms, and requires further study. After all, events that have the character of collective and organizational, remain in the history of the organization longer and are more systemic in nature in the general functioning of the organization, rather than similar processes of individual character. Organizational memory can be considered as a factor in the maintenance, development, and change of the organizational culture, and its functioning mechanisms should be perceived as the functioning mechanisms of these processes.

\section{REFERENCES}

[1] T. Parsons, The system of coordinates and a general theory of action systems: culture, identity and social systems in The American sociological thought: texts (Moscow : University Press, 1994) 462 - 478.

[2] E.Schein, Organizational Culture and Leadership (Jossey-Bass, 1991) .

[3] Factors influencing the characteristics of the organizational culture [Electronic resource]. - Access mode: http://lo1.ru/gos/6/4.htm

[4] Factors influencing organizational culture [Electronic resource]. - Access mode: http: //www.studfiles.ru/preview/5251863/page: 73 /

[5] J. P. Walsh, G. R. Ungson, Organizational Memory Academy of Management. The Academy of Management Review; vol.16, 1, Jan 1991, 57-91. 
[6] T. P. Emelyanova, Collective memory in the context of everyday political consciousness, Information Humanitarian Portal "Knowledge. Understanding. Skill». [Electronic resource]. - Access mode: http://www.zpu-journal.ru/e-zpu/2012/4/Emelianova_Collective-Memory/

[7] M. Halbwachs, Social frame memory, S.N. Zenkina (ed) (Moscow : New Publishing, 2007) [M. Khal'bvaks. Sotsial'nyye ramki pamyati / Per. s fr. i vstupitel'naya stat'ya S.N. Zenkina - M .: Novoye izdatel'stvo, 2007].

[8] R. Merton, Social Theory and Social Structure (Simon and Schuster, 1968). 